\title{
Marine boundary layer structure as observed by A-train satellites
}

\author{
Tao Luo, Zhien Wang, Damao Zhang, and Bing Chen \\ University of Wyoming, Dept. Atmospheric Science, Laramie, WY, USA \\ Correspondence to: Zhien Wang (zwang@uwyo.edu) \\ Received: 23 October 2015 - Published in Atmos. Chem. Phys. Discuss.: 3 December 2015 \\ Revised: 28 April 2016 - Accepted: 3 May 2016 - Published: 13 May 2016
}

\begin{abstract}
The marine boundary layer (MBL) structure is important to the marine low cloud processes, and the exchange of heat, momentum, and moisture between oceans and the low atmosphere. This study examines the MBL structure over the eastern Pacific region and further explores the controlling factors of MBL structure over the global oceans with a new 4-year satellite-based data set. The MBL top (boundary layer height, BLH) and the mixing layer height (MLH) were identified using the MBL aerosol lidar backscattering from the CALIPSO (Cloud-Aerosol Lidar and Infrared Pathfinder Satellite Observations). Results showed that the MBL is generally decoupled with MLH / BLH ratio ranging from $\sim 0.5$ to $\sim 0.8$ over the eastern Pacific Ocean region. The MBL decoupling magnitude is mainly controlled by estimated inversion strength (EIS), which in turn controls the cloud top entrainment process. The systematic differences between drizzling and non-drizzling stratocumulus tops also show dependence on EIS. This may be related to the mesoscale circulations or gravity wave in the MBL. Further analysis indicates that the MBL shows a similar decoupled structure for clear-sky and cumulus-cloud-topped conditions, but is better mixed under stratiform cloud breakup and overcast conditions.
\end{abstract}

\section{Introduction}

The planetary boundary layer is the lowest part of the troposphere that is directly influenced by the Earth's surface. It is considered to be important for the exchange of heat, momentum, and moisture between the surface and the upper troposphere (Stull, 1988). Over oceans, the marine boundary layer (MBL) clouds are frequently present within the MBL, making significant contributions to the energy and moisture budgets of the Earth because of their high albedo (Klein and Hartmann, 1993; Norris and Leovy, 1994; Norris, 1998; Wood and Bretherton, 2004). Despite decades of research efforts, the MBL clouds are still one of the primary contributors to the uncertainty in the model predictions of climate change (Bony and Dufresne, 2005; Randall et al., 2007; Wyant et al., 2015). Because of the close interactions of MBL clouds with the vertical structure and turbulence of the MBL, the representation of convection and MBL processes is critical to the successful climate simulations (Randall et al., 1985; Albrecht et al., 1995; Bony and Dufresne, 2005; Wyant et al., 2010; Zhang et al., 2011).

The decoupling of the MBL is frequently observed at the downwind of the subtropical stratocumulus regions when the turbulence is not strong enough to maintain a wellmixed MBL, especially when the MBL is higher than $1 \mathrm{~km}$ (Bretherton and Wyant, 1997; Wood and Bretherton, 2004; Jone et al., 2011). A wide range of factors controls the MBL decoupling. Bretherton and Wyant (1997) suggested that the decoupling structure is mainly driven by an increasing ratio of the surface latent heat flux to the net radiative cooling in the cloud and that other factors, such as drizzle, the vertical distribution of radiative cooling in the cloud, and sensible heat fluxes, only play less important roles. Meanwhile, Zhou et al. (2015) showed that the entrainment of the dry warm air above the inversion could be the dominant factor triggering the systematic decoupling, while surface latent heat flux, precipitation, and diurnal circulation did not play major roles.

The MBL structure and processes are still not well understood with observations mainly limited to specific case studies in earlier studies (Wood and Bretherton, 2004). The boundary layer structure can be derived from ground-based observations such as sounding (Seidel et al., 2010) or lidar (Emeis et al., 2008). However, ground-based observations of the MBL over the global oceans are sparse and may be not representative. Wood and Bretherton (2004) were the first 
to attempt a combination of MODIS and reanalysis data to study the MBL decoupling, though this passive remote sensing cannot produce direct measurements of MBL structures.

New satellite-based observations allow for innovative ways to observe the boundary layer structure. The global boundary layer height (BLH) climatology has been derived by using Global Positioning System radio occultation (GPSRO) measurements (Ratnam and Basha, 2010; Guo et al., 2011; Ao et al., 2012), the Lidar In-space Technology Experiment (LITE) (Randall et al., 1998), the Geoscience Laser Altimeter System (GLAS) (Palm et al., 2005), and the CloudAerosol Lidar with Orthogonal Polarization (CALIOP) (Jordan et al., 2010; McGrath-Spangler and Denning, 2012, 2013). GPS-RO provides a valuable global view of heightresolved refractivity or moisture structure of boundary layer, but suffers with very coarse spatial resolutions ( $200 \mathrm{~m}$ in vertical and $\sim 200 \mathrm{~km}$ horizontal) and has limited penetration into the lowest $500 \mathrm{~m}$ of the atmosphere (Xie et al., 2012). Satellite-based lidar is sensitive to boundary layer aerosols and clouds, providing global measurements of aerosol properties and their vertical distributions. As the aerosol vertical distribution in the boundary layer is heavily influenced by the boundary layer thermal structure, aerosol structures were used as a good proxy to study the MBL structures (Stull and Eloranta, 1984; Boers et al., 1984; Melfi et al., 1985; Boers and Eloranta, 1986; Leventidou et al., 2013; Luo et al., 2014a; Kong and Fan, 2015).

Earlier studies have shown that satellite-based lidar is effective at deriving global BLH distributions (Randall et al., 1998; Palm et al., 2005; Jordan et al., 2010; McGrathSpangler and Denning, 2012, 2013). This is especially true when using CALIOP observations, because of their much finer vertical $(30 \mathrm{~m})$ and horizontal resolution $(333 \mathrm{~m})$ in the lower troposphere. The aforementioned studies used gradient or variance methods over land and ocean under all-sky or nooptically thick-cloud conditions. Over land, the gradient or variance methods could identify the BLH, which is usually lower than the aerosol layer (Luo et al., 2014a). However, over oceans, the BLH is associated with the aerosol layer top (clear sky) or stratiform cloud top (cloudy sky). Under decoupled MBL conditions, a well-mixed layer usually exists below the BLH with a stronger gradient in aerosol loading near the mixed layer height (MLH) than near the BLH (Luo et al., 2014a). Thus, the aforementioned studies have the potential to report MLH as BLH as they did not fully consider the MBL decoupled structure in choosing lidar methodologies. In the MBL, difficulties in differentiating between the stratiform clouds and cumulus clouds could lead to BLH uncertainties, as the cumulus cloud top heights are often higher than the BLH. Those issues could result in statistical biases in marine BLH distributions differences in reported values and spatial distributions of the BLH over ocean among earlier studies.

After considering the MBL decoupling structure, a new CALIOP-based approach was developed to reliably deter- mine BLH and MLH in order to investigate the clear-sky MBL decouple structure (Luo et al., 2014a). This study uses this new method to investigate the MBL decouple structure over the eastern Pacific Ocean region using CALIOP observations, and combining CloudSat observations with reliable cloud type identification to provide BLH information under stratiform-cloud-topped conditions. The authors also present an examination of the dependence of the MBL decoupled structure on environmental parameters over global oceans. Section 2 describes the data used in this study. Section 3 introduces and evaluates the lidar MBL structure identification methodology with the ship-base observations. Section 4 presents the results and discussions, and brief conclusions are in Sect. 5.

\section{Data}

\subsection{Satellite observations and data collocation}

This study uses multiple remotely sensed and operational meteorological data sets over global oceans during the period from June 2006 to December 2010.

Clear-sky MBL structure was determined from the cloudfree CALIOP measured aerosol backscattering with the cloud-free condition defined as no cloud below $8 \mathrm{~km}$, although cases with optically thin high clouds above $8 \mathrm{~km}$ are included. CALIOP is a dual-wavelength (532 and $1064 \mathrm{~nm}$ ) backscatter lidar, which is carried on the CloudAerosol Lidar and Infrared Pathfinder Satellite Observations (CALIPSO) (Winker et al., 2007, 2009). At $532 \mathrm{~nm}$, the CALIOP provides both the parallel and perpendicular polarization components of attenuated backscatter. The along-track footprint of CALIOP is $333 \mathrm{~m}$ with the vertical resolution of $30 \mathrm{~m}$ below $8.2 \mathrm{~km}$. CALIOP level 1B data provide three calibrated and geo-located lidar profiles of 532 and $1064 \mathrm{~nm}$ total attenuated backscatter (TAB) and $532 \mathrm{~nm}$ perpendicular polarization component. The molecular backscattering was estimated using the temperature and pressure profiles from the ECMWF-AUX (European Center for Medium range Weather Forecasting Auxiliary algorithm; Partain, 2004).

CloudSat carries a $94 \mathrm{GHZ}$ cloud profiling radar (CPR) (Stephens et al., 2002). The CloudSat antenna pattern provides an instantaneous footprint at mean sea level of approximately $1.3 \mathrm{~km}$, while vertically it has 125 bins with a bin size of about $240 \mathrm{~m}$. Cloud top height (CTH) and cloud type were obtained from the 2B-CLDCLASS-LIDAR product (Wang et al., 2012; Sassen and Wang, 2012). This product combines CloudSat and CALIOP observations to better identify the cloud boundaries. In order to produce clear-sky aerosol information, cloudy CALIOP profiles were removed from further averaging. Furthermore, the cloudy BLH was estimated from the CTH of marine stratiform clouds, which was a good proxy for estimating the marine BLH under cloudy condi- 
tions and has been widely used in the previous studies (Minnis et al., 1992; Wood and Bretherton, 2004; Ahlgrimm and Randall, 2006; Zuidema et al., 2009; Karlsson et al., 2010). Classification of drizzle within the cloudy MBL was performed by applying a threshold of $-20 \mathrm{~dB}$ (Leon et al., 2008) to the CloudSat CPR measured reflectivity factor in CloudSat 1B-CPR product (Tanelli et al., 2008).

The atmospheric large-scale stability parameters used in this study include lower tropospheric stability (LTS) (Klein and Hartmann, 1993), and estimated inversion strength (EIS) (Wood and Bretherton, 2006). LTS is calculated using the difference in potential temperature between $700 \mathrm{hPa}$ and the surface $\left(\theta_{700}-\theta_{\text {surface }}\right)$, whereas EIS is the difference between LTS and $\Gamma_{850} \cdot\left(Z_{700}-\mathrm{LCL}\right)$, where $\Gamma_{850}$ is the moist adiabatic lapse rate at $850 \mathrm{hPa}, \mathrm{LCL}$ is lifting condensation level, and $Z_{700}$ is the height at $700 \mathrm{hPa}$. EIS is considered a more precise measure of the strength of a possible inversion than the LTS. EIS and LTS were estimated from AIRS (the Atmospheric Infrared Sounder) level 2 version 5 products (Jason, 2008). AIRS is a grating spectrometer carried on Aqua. It has a spectral resolution of $v / \Delta v \approx 1200$, a total of 2378 channels in the range of 3.7-15.4 $\mu \mathrm{m}$ with a few spectral gaps, and provides well-calibrated level 1B radiances (Overoye, 1999). AIRS is co-registered with the Advanced microwave sounding unit (AMSU) (Pagano et al., 2003; Lambrigtsen and Lee, 2003), and the combined measurements are used to retrieve temperature, humidity, and numerous other surface and atmospheric parameters. Geophysical retrievals are obtained in clear sky and broken cloud cover through the use of a cloud-clearing methodology (Susskind et al., 2006). Though there is no retrieval under overcast conditions, AIRS can provide a reasonable measure of the seasonal mean EIS as compared to model simulations (Yue et al., 2011). Additionally, the AIRS-derived EIS has a strong connection with low clouds (Yue et al., 2011), making the seasonal-mean EIS appropriate for the analysis of the MBL cloud behaviors in this paper.

The sea surface temperature (SST) and surface wind speed at $10 \mathrm{~m}\left(U_{10 \mathrm{~m}}\right)$ were obtained from AMSR-E level 3 daily Ocean Products version 7 (Wentz et al., 2014). The Advanced Microwave Scanning Radiometer - Earth Observing System (AMSR-E) is a twelve-channel, six-frequency, passivemicrowave radiometer system (Kawanishi et al., 2003). It measures horizontally and vertically polarized brightness temperatures at $6.9,10.7,18.7,23.8,36.5$, and $89.0 \mathrm{GHz}$. Spatial resolution of the individual measurements varies from $5.4 \mathrm{~km}$ at $89 \mathrm{GHz}$ to $56 \mathrm{~km}$ at $6.9 \mathrm{GHz}$. AMSR-E is co-located with AIRS and AMSU onboard Aqua and in the A-train with CALIPSO; thus, the instruments are sampling similar conditions and the same time of day. The daily AMSR-E Ocean Products are produced by Remote Sensing Systems (RSS; http://www.remss.com/). The orbital data are mapped to $0.25^{\circ}$ grid box and is divided into two maps based on ascending and descending passes for daytime and nighttime orbits. Error in the data was estimated using the root mean square (rms) difference between AMSR-E $U_{10 \mathrm{~m}}$ and $U_{10 \mathrm{~m}}$ coming from four other satellite microwave radiometers (three Special SensorMicrowave Imager Sounder (SSM/IS) and TRMM (Tropical Rainfall Measuring Mission) Microwave Imager (TMI)) and with $U_{10 \mathrm{~m}}$ from the satellite microwave scatterometer QuikScat (Wentz et al., 2003). This calculation gave an rms difference of $0.92 \mathrm{~m} \mathrm{~s}^{-1}$ with a bias of $0.57 \mathrm{~m} \mathrm{~s}^{-1}$ in AMSR-E $U_{10 \mathrm{~m}}$. The rms difference between AMSR-E SST retrievals and the Reynolds SST is $0.76 \mathrm{~K}$ (Wentz et al., 2003). Validation using data from a buoy (National Data Buoy Center, NDBC) $U_{10 \mathrm{~m}}$ (mean value of $6.61 \mathrm{~m} \mathrm{~s}^{-1}$ ) gave an rms difference with AMSR-E $U_{10 \mathrm{~m}}$ (mean value of $6.46 \mathrm{~m} \mathrm{~s}^{-1}$ ) is $1.63 \mathrm{~m} \mathrm{~s}^{-1}$ with a bias of $-0.15 \mathrm{~m} \mathrm{~s}^{-1}$ (Luo et al., 2015). Validation with NDBC buoy SST (mean value of $299.49 \mathrm{~K}$ ) in this study showed that the rms difference in AMSR-E SST (mean value of $299.26 \mathrm{~K}$ ) is $0.99 \mathrm{~K}$ with a bias of $-0.23 \mathrm{~K}$.

All the related data sets were collocated into AMSR-E $0.25^{\circ}$ grid-box and cloud-free CALIOP backscattering profiles are then averaged. CALIOP backscattering profiles with no cloud below $8 \mathrm{~km}$ (including cases with clouds above $8 \mathrm{~km}$ ) were averaged. Thus, within each $0.25^{\circ}$ grid box, there are three general conditions of the MBL: $100 \%$ cloud cover, partial cloud cover, and cloud-free. For the $100 \%$ cloud cover the BLH is determined from stratiform CTH. For the partial cloud cover and cloud-free conditions, the daily day- or night-averaged cloud-free CALIOP measurements are used to determine BLH and MLH. The following analyses only present data taken over the oceans (within $50^{\circ} \mathrm{N}$ and $50^{\circ} \mathrm{S}$, and at least $200 \mathrm{~km}$ away from continental boundaries), but include both daytime and nighttime observations. The MBL aerosol identifications are the same as in Luo et al. (2014a).

\subsection{MAGIC and collocated satellite observations}

The Marine Atmospheric Radiation Measurement (ARM) GPCI (GCSS Pacific Cross section Intercomparison, a working group of GCSS; GCSS is the Global Energy and Water Cycle Experiment (GEWEX) Cloud Systems Study) Investigation of Clouds (MAGIC) field campaign (http://www.arm. gov/sites/amf/mag/) deployed the US Department of Energy (DOE) Atmospheric Radiation Measurement Program Mobile Facility 2 (AMF2) on the commercial cargo container ship Horizon Spirit from October 2012 to September 2013 with 20 round trips (Lewis et al., 2012; Zhou et al., 2015). The MAGIC transect is the line from the coast of California to Hawaii $\left(35.8^{\circ} \mathrm{N}, 125.8^{\circ} \mathrm{W}\right.$ to $\left.18^{\circ} \mathrm{S}, 173.8^{\circ} \mathrm{W}\right)$ and was undertaken to provide unprecedented, intra-seasonal, highresolution ship-based observations in order to improve the understanding of the $\mathrm{Sc}$-to-Cu (stratocumulus-to-cumulus) transition along this transect. The AMF2 contained a stateof-the-art instrumentation suite and was designed to operate in a wide range of climate conditions and locations, including shipboard deployments. 
This study used atmospheric soundings and MARMETX (marine meteorological measurements) data sets to characterize MBL structure. Standard radiosondes (Vaisala model MW-31, SNE50401) were launched every $6 \mathrm{~h}$ to measure vertical profiles of the thermodynamic state of the atmosphere (temperature, pressure, relative humidity, and wind speed and direction). The MARMETX data set (http://www.arm. gov/campaigns/amf2012magic/) contains standard surface meteorological parameters measured by the MARMETX: temperature $(T)$, pressure $(P)$, relative humidity $(\mathrm{RH})$, and apparent and true wind speed and direction; and the sea surface skin temperature measured by the Infrared Sea surface Temperature Autonomous Radiometer (ISAR) with an accuracy of better than $0.18^{\circ} \mathrm{C}$.

The high spectral resolution lidar (HSRL; Shipley et al., 1983; Piironen and Eloranta, 1994) measuring total attenuated backscattering was also used to document the aerosol and cloud distributions. Because of the high occurrence of the cloud along the MAGIC transect, the lidar-based MBL structure identification method was not applied to the HSRL observations.

To evaluate the satellite-retrieved MBL structure with results from MAGIC soundings, the cloud-free CALIOP observations within a $2.5^{\circ}$ grid box and within 1 day of MAGIC soundings during October 2012 through September 2013 were collocated. The loose restriction was applied in the collocation, because limited MAGIC soundings, poor spatial coverage of CALIOP measurements, and high occurrence of clouds in the region (only $\sim 2 \%$ of the total soundings are under the cloud-free condition). The cloud-free CALIOP profiles were firstly averaged into $0.25^{\circ}$ grid box to improve the signal-to-noise ratio. Then the MBL structure were identified and averaged into the $2.5^{\circ}$ grid box.

\section{MBL structure identification methodology}

\subsection{MBL structure identification methodology for radiosonde}

For radiosonde, the BLH was determined by the Richardson number (RI) method (with the Eq. 2 in Vogelzang and Holtslag, 1996). This method determines the BLH as the height at where RI is larger than the critical value (i.e., 0.25). The RI method is suitable for both stable and convective boundary layers. This method gives the BLH more physical meaning as it relates the derived BLH to boundary layer processes - surface heating, wind shear, and capping inversion. Also, the RI method does not produce a negative BLH, as it does not depend strongly on the sounding vertical resolution of the sounding. Therefore, the RI method is often considered as the best estimation against which to evaluate lidar-based BLH estimations (Hennemuth and Lammert, 2006; Seidel et al., 2010).
Figure 1 presents one transect HSRL and potential temperature from MAGIC measurements. It is clear that the BLHs from the RI method correspond well with the aerosol layer tops, or stratiform clouds tops over the stratiform cloud region (a longitude east of $\sim-137^{\circ}$ ). There is also some correspondence of BLHs with the highest cumulus clouds tops over the cumulus cloud region (a longitude west of $\sim-137^{\circ}$ ). Over the cumulus cloud region the MBL becomes obviously decoupled, and there is usually one or more weak inversion layers below the RI determined BLH. The lowest inversion layer usually limits the upward transportation of the aerosols to form a layer, forming a layer with more concentrated aerosols than that above (this can also be seen in Fig. 4 in Luo et al., 2014a). This inversion can also limit the vertical developments of the small cumulus clouds that may form in the mixing layer. This characteristic allows for the identification of MLH height as the base of the lowest inver-

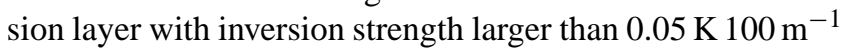
in radiosonde potential temperature profiles. This threshold was chosen based on a visual check of all MAGIC transects.

\subsection{MBL structure identification methodology for CALIOP}

As detailed in Luo et al. (2014b), the BLH can be determined with an improved threshold method using a threshold $\beta_{\mathrm{thr}}^{\prime}=\beta_{\mathrm{m}}^{\prime}+2 \cdot \mathrm{MBV}$ applied to the marine aerosol backscattering coefficient profile retrieved from collocated CALIOP level 1B data. In this equation, $\beta_{\mathrm{m}}^{\prime}$ is the molecular backscattering coefficient, estimated by temperature and pressure profiles from ECMWF-AUX products; MBV is the measured backscatter variation, estimated as the standard deviation of measured attenuated backscatter coefficients from 30 to $40 \mathrm{~km}$.

The MLH was identified by the gradient method (Luo et al., 2014a). The gradient of aerosol backscattering coefficient is calculated after a 3-point moving-average smoothing. After smoothing, the MLH is determined to be the lowest point with an aerosol backscattering coefficient gradient larger than 2 times that of the molecular backscattering gradient.

The evaluation of lidar methodology with radiosonde soundings were performed with 2-year (2007-2008) clearsky ARM program Climate Research Facility (ACRF) radiosonde and micro-pulse lidar (MPL) observations (Xie et al., 2010; Mather and Voyles, 2013) collected from Nauru (marine site). Detailed data processes can be found in Luo et al. (2014a). When compared to radiosonde-derived BLH, the bias and root mean square error (RMSE) of MPL-derived BLH is $-0.12 \pm 0.24 \mathrm{~km}$ with a correlation coefficient of 0.75 . When compared to radiosonde-derived MLH, the bias and RMSE of MPL-derived MLH is $-0.06 \pm 0.16 \mathrm{~km}$ with a correlation coefficient of 0.66 . An overall comparison of radiosonde-derived to MPL-derived MLH / BLH produces a bias and RMSE of $-0.02 \pm 0.1$ as well as a correlation coef- 


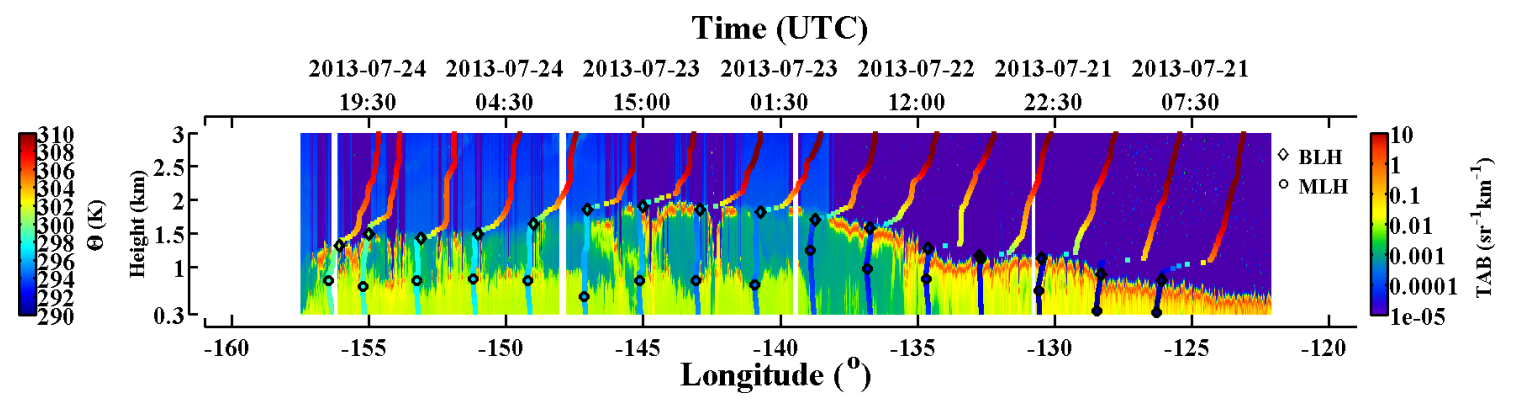

Figure 1. Potential temperature profiles and retrieved MBL structure (black diamonds for BLH and black circles for MLH) for a MAGIC leg from 21 to 24 September 2013, overlaid with total attenuated backscattering from HSRL.

ficient of 0.61. All the correlation coefficients are reported at a confidence level of 0.01 . These values of mean bias indicate that our lidar-based BLH and MLH determinations for clear-sky MBL can be considered accurate.

Further evaluations were performed with loosely collocated CALIOP and MAGIC observations. While only cloudfree CALIOP profiles can be used to derive the MBL structure, the soundings were measured in all-sky conditions (mostly cloudy conditions) (Fig. 1). Figure 2 shows the comparisons of MBL structure between radiosonde and CALIOP measurements. The mean MBL structure by CALIOP and radiosonde along the MAGIC transect is shown in Fig. 2a. Both results show a similar trend in the MBL structure, being less decoupled near the coast and more decoupled over the far ocean. The heights of the CALIOP-derived BLH and MLH are lower than those derived from the radiosonde. Over the stratiform cloud regions, the CALIOPderived MBL structure appears more decoupled than in the radiosonde results, which could result from different cloud conditions sampled by these two observation data sets. However, the CALIOP-derived BLH shows good agreement with those from radiosonde as shown in Fig. $2 b$. The bias and RMSE in CALIOP-derived BLH were calculated to be $-0.14 \pm 0.37 \mathrm{~km}$, with a correlation coefficient of 0.56 at the confidence level of 0.01 . For CALIOP-derived MLH, the bias and RMSE is $-0.1 \pm 0.45 \mathrm{~km}$ with a correlation coefficient of 0.34 at the confidence level of 0.01 . Although the biases are small, the RMSE differences are large, mainly as a result of limited sampling and large spatial mismatch, and different cloud conditions. This is especially true over the stratiform cloud region where the cloud fraction in the MBL is very high (Fig. 1). In this area the collocated cloud-free CALIOP profiles are often too far from the sounding observations to produce a strong correlation. However, Fig. 2 clearly shows that the CALIOP-observed clear-sky MBL structure captures a similar spatial trend to those from the nearby cloudy-sky MBL.

Additionally, the radiosonde-derived MLH agrees well with the LCL (Fig. 2b), with the bias and RMSE of $-0.13 \pm 0.21 \mathrm{~km}$, and with a correlation coefficient of 0.73 at the confidence level of 0.01 . Figure $2 \mathrm{~d}$ shows the compar-
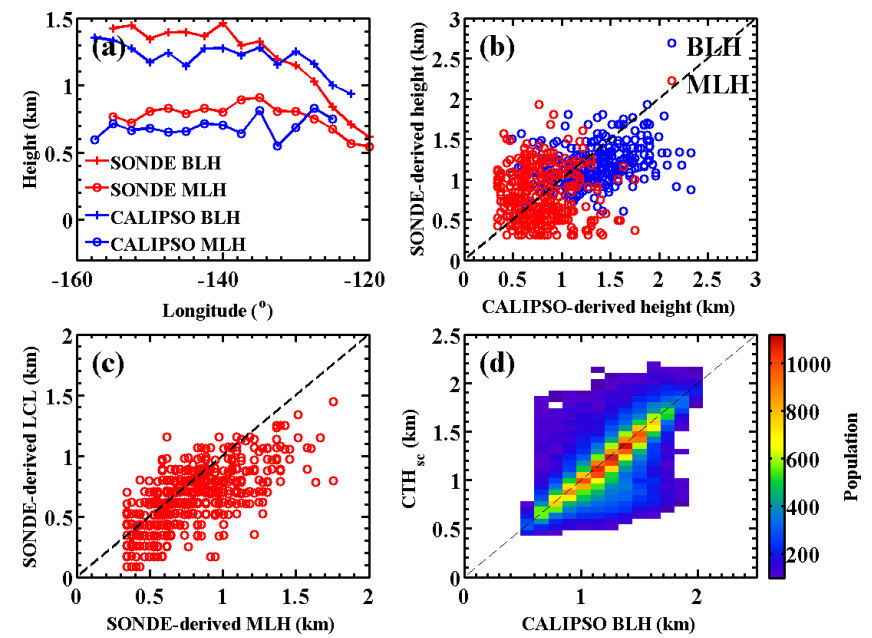

Figure 2. (a) Mean MBL structure along longitude from MAGIC radiosonde and collocated CALIOP observations; (b) comparisons of radiosonde and CALIOP-derived BLH and MLH; (c) comparison of radiosonde-derived MLH and LCL; (d) comparison of CALIOPderived BLH and stratiform cloud top $\left(\mathrm{CTH}_{\mathrm{sc}}\right)$.

ison between the CALIOP-derived BLH and stratiform CTH $\left(\mathrm{CTH}_{\mathrm{sc}}\right)$ within the same AMSR-E grid box over the eastern Pacific Ocean region. The bias and RMSE of the CALIOPderived BLH is $-0.06 \pm 0.52 \mathrm{~km}$ with a correlation coefficient of 0.66 at the confidence level of 0.01 . The large RMSE may relate to cloud top detrainment or cloud edge local circulations. However, the mean bias of $0.06 \mathrm{~km}$ corresponds to a uncertainty of $\sim 5 \%$ mean BLH. Good agreement between the CALIOP-derived BLH and $\mathrm{CTH}_{\mathrm{sc}}$ can also be found over the global oceans (Luo et al., 2014a).

\section{Results and discussions}

\subsection{MBL structure over the eastern Pacific Ocean}

This section uses the 4-year new MBL and marine boundary layer cloud (MBLC) data set described in the previous section to investigate the MBL structure over the eastern Pacific. 

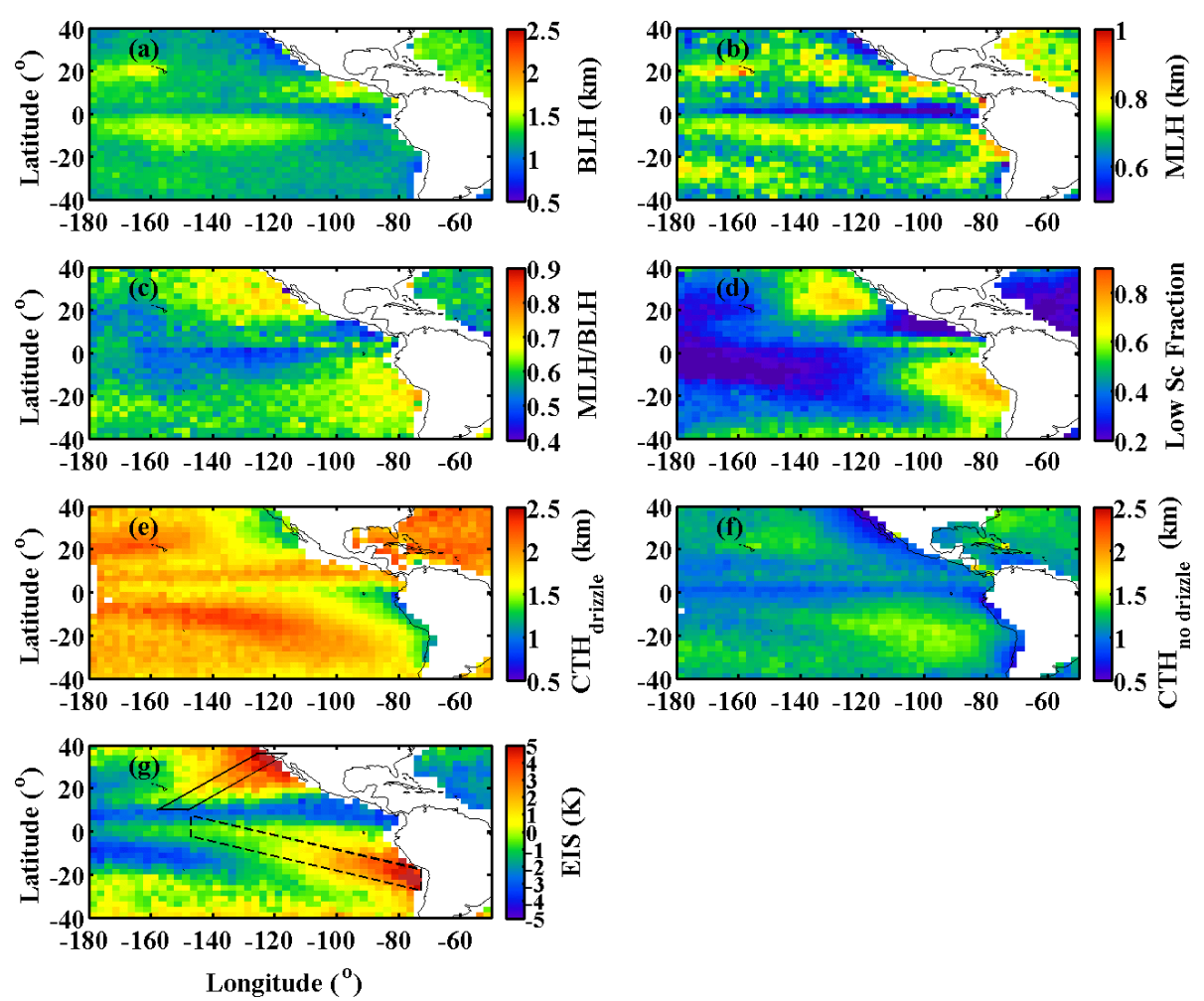

Figure 3. The spatial distribution of (a) CALIOP-derived BLH, (b) CALIOP-derived MLH, (c) CALIOP-derived MBL decoupling structure in term of $\mathrm{MLH} / \mathrm{BLH}$, (d) marine low clouds fraction, (e) drizzled stratiform CTH $\left(\mathrm{CTH}_{\text {drizzle }}\right)$, (f) non-drizzled stratiform CTH $\left(\mathrm{CTH}_{\text {nodrizzle }}\right)$, and (g) EIS. The solid and dashed boxes in (g) denote the selected transects on the northeastern and southeastern Pacific Ocean (NPO and SPO) used in Figs. 4 and 5, respectively.

The MBLC data set includes cloud type and stratiform-cloud (Sc) top and drizzle information based on the CloudSat products. Figure 3 shows the 4-year mean MBL structure (BLH, MLH, and MLH / BLH), $\mathrm{CTH}_{\mathrm{sc}}$ (with or without drizzle), EIS, and $U_{10 \mathrm{~m}}$ over the eastern Pacific Ocean. Hereafter, the MBL structure (BLH, MLH, and MLH / BLH) is referred to as the clear-sky condition with aerosols as a proxy, while the CTHsc is used as the proxy of BLH under cloudy conditions.

The 4-year mean BLH over the eastern Pacific Ocean is shown in Fig. 3a. Figure 3a shows that the marine BLH is lower than $\sim 1 \mathrm{~km}$ near the coastal region at latitude of $\sim \pm 30^{\circ}$. This is assumed to be due to the strong subsidence and low SST. When moving away from the strong subsidence region, the BLH increases. The BLH is highest over the Intertropical Convergence Zone (ITCZ), which is attributed to large-scale convergence and the high SST causing strong buoyancy-driven vertical turbulence mixing. This is especially prevalent over the eastern Pacific near Central America. However, the BLH is low along the Equator with a tendency to rise heading westward. The 4-year mean MLH (Fig. 3b) shows a similar spatial pattern as the BLH, with a correlation coefficient of 0.6 at a confidence level of 0.01. The rising trend of BLH when away from the coast was also illustrated in former satellite-based studies (Rat- nam and Basha, 2010; Guo et al., 2011; Ao et al., 2012; Randall et al., 1998; Palm et al., 2005; Jordan et al., 2010; McGrath-Spangler and Denning, 2012, 2013). However, due to different methodologies associated with a different definition of BLH and the filtering of cloud conditions, this study shows a significant magnitude of differences in BLH from former studies. As an example, the BLH reported in McGrath-Spangler and Denning (2013) is much lower than the BLH seen in our results, but there is similarity in pattern and value of our MLH and the McGrath-Spangler and Denning BLH over the eastern Pacific Ocean.

The 4-year mean MBL coupling status in terms of averaged ratio of MLH / BLH is shown in Fig. 3c. The better mixed the MBL, the larger the ratio of MLH / BLH. This is shown in the stratiform cloud dominated region (where Sc Fraction $>\sim 0.4$ with stronger EIS and lower BLH) where there is higher MLH / BLH than in the cumulus cloud dominated region (where Sc Fraction $<\sim 0.4$ with weaker EIS and higher BLH). The MBL is obviously decoupled over the ITCZ. The MBL shows better mixing from 100 to $80^{\circ} \mathrm{W}$ of the Equator, but weak mixing from 160 to $100^{\circ} \mathrm{W}$ of the Equator; the decoupling trend of the MBL is present westward along the Equator. 

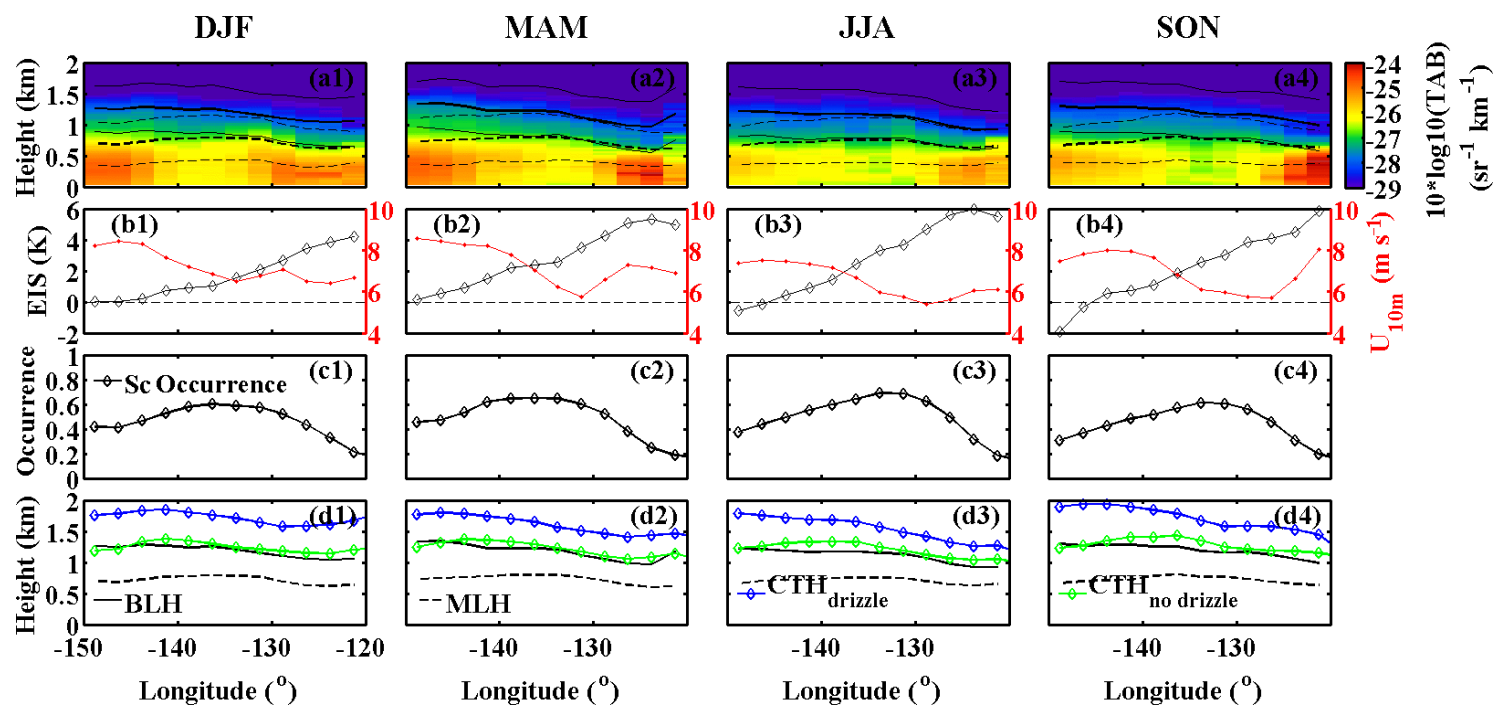

Figure 4. The satellite MBL observations along the transect region on the northeastern Pacific Ocean (NPO; solid box in Fig. 3e) in different seasons: (a1-a4) the mean BLH (solid line) and MLH (dashed line) overlaid with TAB, and corresponding standard deviations (thin solid and dashed lines); (b1-b4) EIS (black diamond line) and $U_{10 \mathrm{~m}}$ (red dot line); (c1-c4) stratocumulus (Sc) occurrence; (d1-d4) comparisons of BLH, MLH, $\mathrm{CTH}_{\text {drizzle }}$, and $\mathrm{CTH}_{\text {no drizzle. }}$

Sc occurs more frequently (Sc fraction $>\sim 0.6$ ) when EIS $>\sim 1 \mathrm{~K}$, with a decreasing fraction towards the far ocean, as shown in Fig. 3d. Sc occurrence depends on the EIS (Fig. 3g), with a correlation coefficient of 0.78 at confidence level of 0.01 in their spatial patterns. Figure $3 \mathrm{e}$ and $\mathrm{f}$ show Sc tops with and without drizzle. The Sc case is defined as the case where there are only Sc (and clear sky if it has) profiles in the collocated $0.25^{\circ}$ grid box (the Sc fraction $>0$ ). These cases are then broken into the $\mathrm{Sc}$ case with and without drizzle. The Sc case with drizzle is the Sc case where at least one $\mathrm{Sc}$ profile in the collocated $0.25^{\circ}$ grid box has drizzle, while the remaining Sc cases are non-drizzled Sc case. The drizzled Sc tops are lower than $\sim 1.5 \mathrm{~km}$ when near the coast where the stratus cloud is dominant, and the drizzled Sc tops rise up to $\sim 2.5 \mathrm{~km}$ as distance away from the coast increases. The non-drizzled Sc tops show a similar pattern to the drizzled Sc top (with a correlation coefficient of 0.53 at confidence level of 0.01 in their spatial pattern), except that the non-drizzled Sc tops are lower when approaching the tropical Pacific near a longitude of $\sim 180^{\circ} \mathrm{W}$. Generally, the drizzled Sc top is $\sim 0.2$ to $1 \mathrm{~km}$ higher than the non-drizzle Sc top, which suggests the important role of the meso-scale circulations in MBL. Precipitation more commonly occurs in updraft regions and the breakup of Sc usually happens in downdrafts areas, which was also observed in the rift area of Sc (Sharon et al., 2006) and in MAGIC (Zhou et al., 2015). Furthermore, the occurrence of the drizzled Sc case is $\sim 6.2 \%$ (the number of Sc profiles with drizzle/the number of Sc profiles) among MBL cases where a $0.25^{\circ}$ grid box contains both Sc and clear sky, compared to $\sim 32 \%$ of all MBL cases being stratiform cloud with drizzle cases. The
Sc cases containing clear-sky profiles are where broken Sc clouds or a cloud edge enter a $0.25^{\circ}$ grid box. This relationship indicates that heterogeneous cloudy conditions within a grid box (i.e., broken Sc clouds or near the cloud edge) are less likely to produce precipitation than where the conditions are more homogeneously cloudy.

The detailed assessments of the seasonal MBL and MBLC structures in the two selected transects over the northeastern and southeastern Pacific Ocean (NPO and SPO) are presented in Figs. 4 and 5. Figures 4 and 5 (panels a1-a4) show the seasonal mean MBL structure in terms of MBL aerosol loading, overlain with seasonal mean BLH and MLH. The mean BLH, MLH, and their standard deviations show that the MBL tends to be more frequently well mixed near the coastal region and be more frequently decoupled over the far ocean. This corresponds to a stronger EIS near the coast and weaker EIS over the far ocean (the black diamond-solid lines in Figs. 4 and 5, panels b1-b4). The EIS over the NPO shows negative correlation with the $U_{10 \mathrm{~m}}$, with a correlation coefficient of -0.64 at confidence level of 0.01 , but there is a positive correlation with the $U_{10 \mathrm{~m}}$ when EIS $<3 \mathrm{~K}$ over the SPO, with a correlation coefficient of 0.6 at confidence level of 0.01 . The seasonal variations in the MBL structure are small over both the NPO and SPO regions, except that the MBL tends to be lower and better mixed near the coastal region during March, April, and May (MAM) and June, July, and August (JJA) over the NPO, and in JJA and September, October, and November (SON) over the SPO. This is likely associated with the stronger EIS $(>5 \mathrm{~K})$ in these seasons than EIS $(<5 \mathrm{~K})$ in the other seasons. 

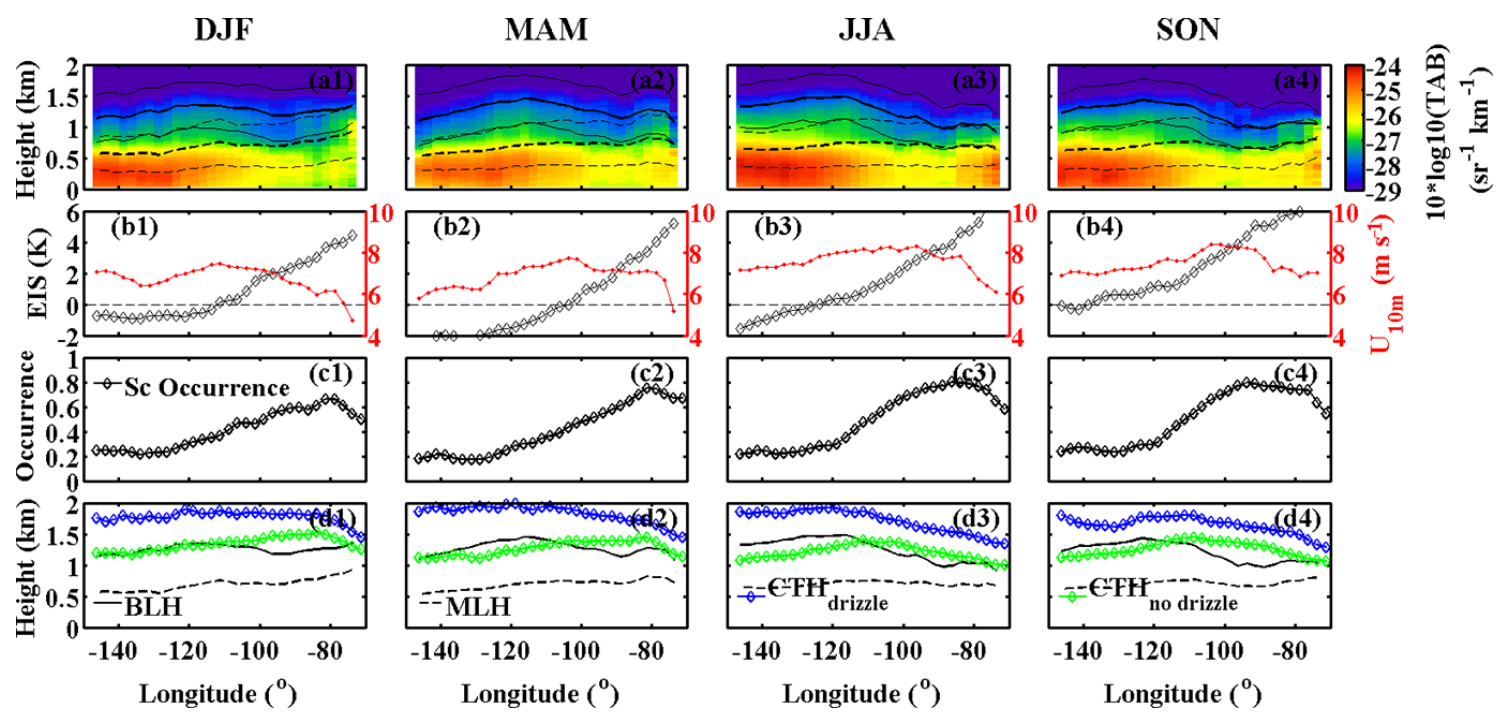

Figure 5. Same as Fig. 4 but for the transect region on the southeastern Pacific Ocean (SPO; dashed box in Fig. 3e) in different seasons.

Surface wind speed is the main factor controlling the loading of sea salt aerosols near the surface, while its vertical distribution is closely related to the boundary layer processes (Luo et al., 2014b). When moving away from the coast, the aerosol loading (Figs. 4 and 5, panels a1-a4) in the wellmixed layer shows strong positive correlation with the $U_{10 \mathrm{~m}}$ in NPO with a correlation coefficient of 0.64 at the confidence level of 0.01 . However, there is almost no correlation between them in the SPO (correlation coefficient of -0.08 at the confidence level of 0.39). In the SPO, when further east than a longitude of $\sim-100^{\circ}$, the aerosol loading in the lower well-mixed layer increases with decreasing of the $U_{10 \mathrm{~m}}$. This is attributed to lowering MLH limiting the vertical transportation. When near the coastal region, the aerosol loading in the well-mixed layer has weak correlation with the $U_{10 \mathrm{~m}}$ over both regions, possibly due to the aerosol transported from the continent.

Figures 4 and 5 (panels c1-c4) show the mean Sc occurrences over the two regions. Over the NPO region (Fig. 4, panels c1-c4), the Sc occurrence is small near the coast and increases to a maximum of $\sim 0.6$ near the longitude of $\sim-130$ to $-135^{\circ}$. It then decreases west southward towards the tropics. Over the NPO, the Sc occurrence increases with decreasing of EIS when moving away from the coast to the maximum occurrence point (at longitude of $\sim-135^{\circ}$ ), with a correlation coefficient of -0.51 at the confidence level of 0.01 ; a positive correlation with EIS is shown from the maximum occurrence point down to the Equator, with a correlation coefficient of 0.92 at the confidence level of 0.01 . Over the SPO region (Fig. 5, panels c1-c4), the maximum Sc occurrence point is close to the coast. Therefore, the Sc occurrence and the EIS both decrease when far away from the coast and correlate well with each other when further west than a longitude of $\sim-80^{\circ}$, with a correlation coefficient of 0.91 at the confidence level of 0.01 . In the near-coastal region, other processes, such as sea-land breeze and cold current producing cold SST, could affect the relationship between EIS and Sc occurrence. The drizzle occurrence showed a weak correlation with EIS in both regions (not shown here).

Figures 4 and 5 (panels d1-d4) show the seasonal mean $\mathrm{CTH}_{\text {drizzle }}$ (blue diamond line) and $\mathrm{CTH}_{\text {no drizzle }}$ (green diamond line) along with the seasonal mean BLH and MLH over the NPO and SPO. The $\mathrm{CTH}_{\text {no drizzle }}$ is lower than the $\mathrm{CTH}_{\text {drizzle }}$, but is close to the BLH. Over the NPO region, the $\mathrm{CTH}_{\text {drizzle }}$ shows strong negative correlation with the EIS, with a correlation coefficients of $<-0.82$ at the confidence level of 0.01. Over the NPO region, in MAM, JJA, and $\mathrm{SON}$, the $\mathrm{CTH}_{\text {drizzle }}$ shows strong negative correlation with the EIS, with a correlation coefficients of $<-0.77$ at the confidence level of 0.01 , while there is a very weak correlation in December, January, and February (DJF), with a correlation coefficients $<-0.33$ at the confidence level of 0.08 . The $\mathrm{CTH}_{\text {no drizzle }}$ generally shows a weak correlation with the EIS, although there is a positive correlation with the EIS for sub-regions, such as over the SPO when west of a longitude of $\sim-90^{\circ}$ in DJF and MAM and when west of a longitude of $\sim-100^{\circ}$ in JJA and SON, with a correlation coefficients of $>0.64$ at the confidence level of 0.01 . The difference between $\mathrm{CTH}_{\text {drizzle }}$ and $\mathrm{CTH}_{\text {no drizzle }}$ shows strong dependence on the EIS; i.e., there is a smaller difference associated with stronger EIS and a larger difference associated with weaker EIS. This is attributed to a stronger EIS indicating a more stable MBL, which allows for small depth variations associated with several possible vertical displacement forces in MBL. Thus, a small difference between $\mathrm{CTH}_{\text {drizzle }}$ and $\mathrm{CTH}_{\text {no drizzle }}$ is expected under stronger EIS.

The MBL activities are strongly connected with the largescale stabilities. Figure 6 shows the relationships between 

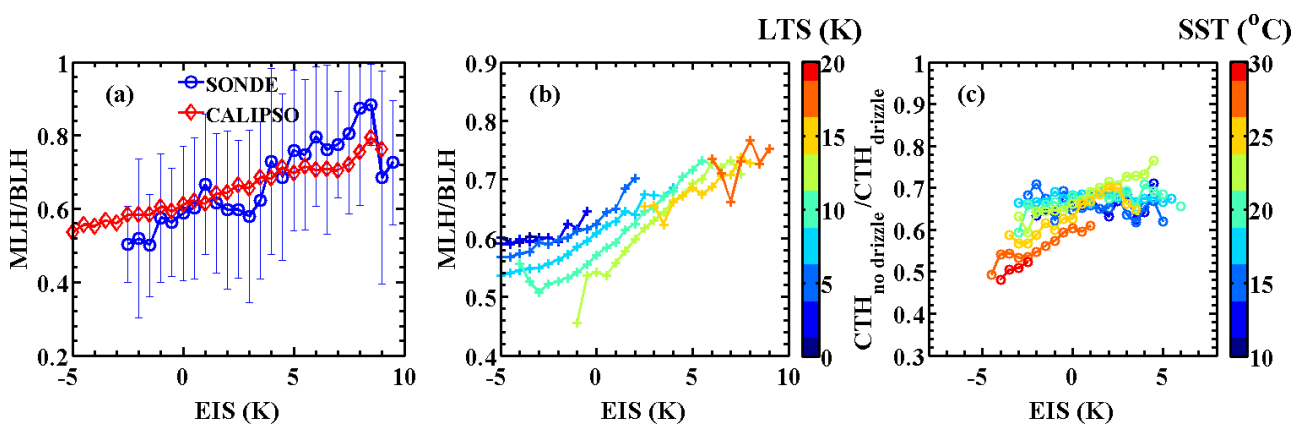

Figure 6. (a) Relationship with EIS and MLH / BLH in MAGIC and satellite observations over extended MAGIC region; (b) relationship between EIS and CALIOP-derived MLH / BLH under different LTS over the global oceans; (c) seasonal mean relationship between EIS with $\mathrm{CTH}_{\text {no drizzle }} / \mathrm{CTH}_{\text {drizzle }}$ under different SST over the global oceans. The standard deviations (not shown in panels $\mathbf{b}$ and $\mathbf{c}$ ) for data in the panels (a) and (b) are $\sim 0.2$, and $\sim 0.1$ in (c).

EIS and MBL coupling structure. In Fig. 6a, MAGIC observations and CALIOP observations over the extended MAGIC region were sorted and averaged into different bins of EIS. Both observations from MAGIC radiosonde and CALIOP show the MBL tends to be better mixed as EIS increases. One of the main parameters controlling the entrainment process is the inversion strength near the mixing layer top (Vanzanten et al., 1999). According to the definition of EIS, it implies that a stronger EIS leads to a stronger inversion near the mixing layer top, and a weaker entrainment of the dry warm air above the inversion. Therefore, the relationship between EIS and MBL structure suggests that the entrainment of the dry warm air above the inversion could be an important factor controlling the MBL decoupling. It could also be expected that the SST, wind shear, and surface heat flux may also affect MBL decoupling as these parameters or processes can also affect the entrainment process (Vanzanten et al., 1999). However, analyses of $U_{10 \mathrm{~m}}$ and SST show only very weak correlations with MBL coupling structure. This is possibly due to the uncertainties in satellite retrievals of these parameters or that the role of other factors was partially included in the EIS.

After further investigation, we concluded that the MBL coupling structure is controlled by both LTS and EIS when EIS $<\sim 3 \mathrm{~K}$; i.e., there is greater mixing in the MBL with increasing EIS and decreasing of LTS. Figure $6 \mathrm{~b}$ shows the mean CALIOP-derived MBL coupling structure over global oceans under binned EIS and LTS values. As shown in Fig. 6b, the mean MBL coupling structure in terms of MLH / BLH shows good correlation with EIS under different bins of LTS when LTS is between 2.5 and $17.5 \mathrm{~K}$ (correlation coefficient of $>0.88$ at confidence level of 0.01). Furthermore, the MBL coupling structure in term of MLH / BLH shows a very strong negative correlation with LTS when binned EIS $<2 \mathrm{~K}$ (correlation coefficient $<-0.95$ at confidence level of 0.01). Under the same EIS, our observation shows that weaker LTS cases usually correspond to cases with larger sea-air temperature difference (corresponding to larger latent heat flux) and higher $U_{10 \mathrm{~m}}$, which prompt stronger turbulence mixing and result in deeper mixing layers. Therefore, weaker LTS under the same EIS implies less decoupling. However, further investigation is needed to understand the essential connection between the large-scale stability and near-surface turbulence parameters by combining observations and model simulations.

The differences between drizzling and non-drizzling Sc tops are also controlled by the EIS. Figure $6 \mathrm{c}$ shows the seasonal mean relationship over the global oceans between EIS and $\mathrm{CTH}_{\text {no drizzle }} / \mathrm{CTH}_{\text {drizzle }}$ binned by SST. The SST, EIS, and $\mathrm{CTH}_{\text {no drizzle }} / \mathrm{CTH}_{\text {drizzle }}$ were averaged across a $2.5^{\circ} \times 2.5^{\circ}$ grid box and different seasons. After this, the seasonal-mean $\mathrm{CTH}_{\text {no drizzle }} / \mathrm{CTH}_{\text {drizzle }}$ was sorted and averaged into different bins of EIS and SST. This binning showed that with cold SST (SST $<=20^{\circ} \mathrm{C}$ ) in the middle to high latitude regions, mean $\mathrm{CTH}_{\text {no drizzle }} / \mathrm{CTH}_{\text {drizzle }}$ does not vary with EIS, whereas in the Sc-to-Cu transition regions where there is warm SST $\left(\mathrm{SST}>20^{\circ} \mathrm{C}\right)$, the mean $\mathrm{CTH}_{\text {no drizzle }} / \mathrm{CTH}_{\text {drizzle }}$ shows good dependence on EIS (a correlation coefficient $>0.89$ at confidence level of 0.01 ). The relative difference between $\mathrm{CTH}_{\text {drizzle }}$ and $\mathrm{CTH}_{\text {no drizzle }}$ becomes larger with decreasing EIS and increasing SST, indicating more vigorous the subsidence and uplifting in the MBL under weak EIS conditions and warmer SST. This result suggests that the subsidence and uplifting may relate to meso-scale processes, such as gravity waves, which can be generated from the geostrophic adjustment, jet break or other sources, affecting the morphology of clouds (Jiang and Wang, 2012; Allen et al., 2013) over the Sc-to-Cu transition regions. The different roles of SST and EIS in controlling Sc top and precipitation generation in different regions will be further investigated in future studies.

\subsection{Discussion}

The MBL decoupling was suggested to play an important role in Sc-to-Cu transition (Bretherton and Wyant, 1997; Wood and Bretherton, 2004). The MBL structure is shown in 

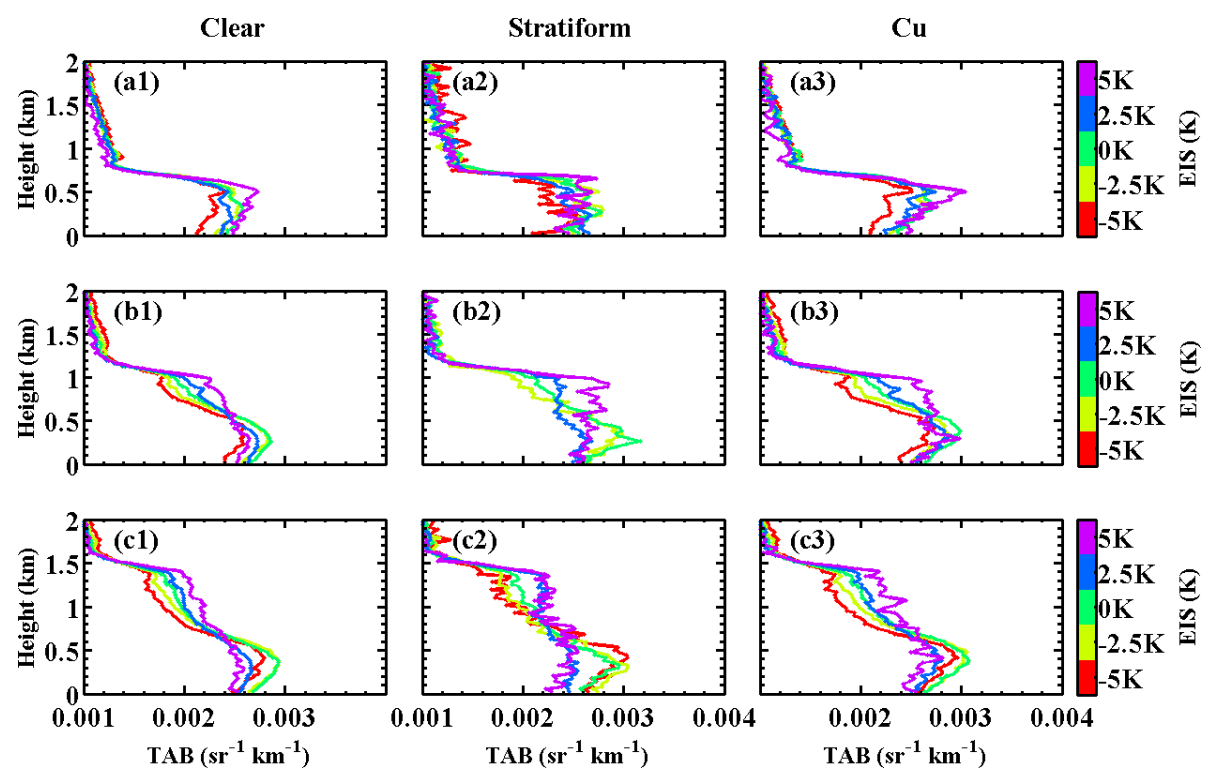

Figure 7. Mean MBL CALIOP TAB structure under different conditions from 4-year climatology over the eastern Pacific Ocean: $0.6 \mathrm{~km}<\mathrm{BLH}<0.8 \mathrm{~km}(\mathbf{a 1}, \mathbf{a 2}, \mathbf{a 3}), 1 \mathrm{~km}<\mathrm{BLH}<1.2 \mathrm{~km}(\mathbf{b 1}, \mathbf{b 2}, \mathbf{b 3})$, and $1.4 \mathrm{~km}<\mathrm{BLH}<1.6 \mathrm{~km}(\mathbf{c 1}, \mathbf{c 2}, \mathbf{c 3})$. (a1, b1, c1) are under the clear conditions that are defined as totally cloud free over a $0.25^{\circ}$ AMSR-E footprint; (a2, b2, $\left.\mathbf{c 2}\right)$ are under the stratiform cloud conditions that are defined as with only stratiform cloud and clear sky in each $0.25^{\circ}$ AMSR-E footprint; (a3, b3, c3) are under the Cu cloud conditions that are defined as with only $\mathrm{Cu}$ cloud and clear sky in each $0.25^{\circ}$ AMSR-E footprint. Only results with $5 \mathrm{~m} \mathrm{~s}^{-1}<U_{10 \mathrm{~m}}<8 \mathrm{~m} \mathrm{~s}^{-1}$ were included.

Fig. 7 as the mean of aerosol backscattering from the cases with both clear sky and stratiform/ $\mathrm{Cu}$ cloud in the same $0.25^{\circ}$ grid box over the eastern Pacific Ocean where the Sc-to- $\mathrm{Cu}$ transition frequently happens. The clear condition is defined as totally cloud free in the $0.25^{\circ}$ AMSR-E footprint (named as clear MBL). This condition is expected to be less affected by the local circulation associated with the cloud development. Aerosols under the stratiform cloud condition are derived from cases with partially stratiform cloud and partially clear sky in a $0.25^{\circ}$ AMSR-E footprint (named as stratiform $\mathrm{MBL}$ ). Aerosols under the $\mathrm{Cu}$ cloud condition are derived from cases with partially $\mathrm{Cu}$ cloud and partially clear sky in a $0.25^{\circ}$ AMSR-E footprint (named as Cu MBL). According to the comparison of CALIOP-derived clear-sky MBL structure with nearby cloudy-sky MBL structure from MAGIC radiosonde and with the nearby stratiform cloud top from 2B-CLDCLASS-LIDAR in Sect. 3.2, it is reasonable to assume that the cloud-topped MBL can have the similar structure to the nearby clear-sky MBL within a $0.25^{\circ}$ footprint for the Sc and $\mathrm{Cu}$ MBL cases. Figure 7 shows that the clear MBL and $\mathrm{Cu}$ MBL become more decoupled with increasing BLH and decreasing EIS as indicated by large vertical gradients between mixing layer aerosols and near MBL top aerosols. The stratiform MBL shares similar characteristics to the $\mathrm{Cu}$ MBL, but are better mixed than clear MBL and $\mathrm{Cu}$ MBL when EIS $>0$. According to Fig. 3, the region with EIS $<0 \mathrm{~K}$ is the $\mathrm{Cu}$ cloud dominated region (where the fraction of Sc cloud is smaller than 0.2), and the Sc MBL cases here are more likely to be associated with the clear-sky MBL adjacent to the small Sc. The region of $0 \mathrm{~K}<$ EIS $<2.5 \mathrm{~K}$ is considered a transition region where the Sc clouds are broken down and transit to $\mathrm{Cu}$ clouds. The stratiform MBL cases with $0 \mathrm{~K}<$ EIS $<2.5 \mathrm{~K}$ are more likely associated to the clear-sky MBL adjacent to broken Sc. The stratiform MBL cases with EIS $>2.5 \mathrm{~K}$ are more likely associated with the clear-sky MBL near the edge of overcast Sc in the region where Sc fraction $>\sim 0.6$. When EIS $<0 \mathrm{~K}$, the stratiform MBL showed no major difference between clear MBL and $\mathrm{Cu}$ MBL. With increasing EIS, corresponding to increasing amount of stratiform clouds, the presence of large-scale subsidence prompts a well-mixed MBL, or more occasionally a decoupled MBL with two well-mixed sub-layers (Fig. 7, panel c2).

\section{Conclusions}

This paper used 4-year satellite observations to investigate the MBL decoupled structure and its spatial distribution over the eastern Pacific region and its dependence on environmental parameters over global oceans (within latitude of $\pm 50^{\circ}$ ). The aerosol information in CALIOP-measured backscattering data is considered to be a good proxy for the MBL decoupled structure. The aerosol layer top is a good indicator for BLH and was able be identified by the threshold method, whereas the MLH could be identified by the gradient methods. The lidar determined BLH showed good agreements 
with BLH determined by the RI method using radiosonde measurements and with the stratiform cloud top from CloudSat product. The lidar determined MLH showed good agreement with the base of lowest inversion layer in radiosonde temperature profiles.

The lidar methodology was then applied to the 4-year satellite observations over the eastern Pacific Ocean. Clearsky MBL structure characteristics were analyzed together with the cloudy MBL top (inferred from the stratiform cloud top). For the first time, the climatology and seasonal variations of the MBL structure in the eastern Pacific Ocean region were presented and analyzed. This analysis showed that MBL is generally decoupled, with MLH / BLH ratio ranging from $\sim 0.5$ to $\sim 0.8$ over the eastern Pacific Ocean region. The MBL decoupling magnitude is mainly controlled by EIS that affects the cloud top entrainment process, with a correlation coefficient of $>0.88$ at a confidence level of 0.01 between the mean MBL coupling structure in terms of MLH / BLH and EIS when binned LTS is between 2.5 and $17.5 \mathrm{~K}$. The systematic differences between drizzling and non-drizzling Sc tops over the Sc-to-Cu transition region also show dependence on EIS and may relate to the meso-scale circulations driven by gravity wave in MBL. Further analysis showed that the MBL shows similar decoupled structure under clear-sky and cumulus-cloud-topped conditions, but is better mixed under Sc breakup and overcast conditions.

This study demonstrated that satellite lidar measurements offer a unique opportunity to characterize MBL over global oceans, something not possible using other techniques. Multi-satellite measurements also offer a chance to further study related MBL processes. Using observational results presented here, it will be possible to evaluate and improve model MBL simulations under different dynamical and thermodynamical conditions.

Acknowledgements. This research was partially funded by the DOE grant DE-SC0006974 as part of the ASR program and by the NASA grant NNX13AQ41G. We would also like to thank anonymous reviewers for their positive and constructive comments. The authors would like to thank the Editor's effort in improving this manuscript. The authors would like to thank CloudSat team for providing data from the CloudSat Data Processing Center (http://www.cloudsat.cira.colostate.edu). The authors would like to thank the CALIOP team for providing data obtained from the NASA Langley Research Center Atmospheric Science Data Center. AMSR data are produced by Remote Sensing Systems and were sponsored by the NASA AMSR-E Science Team and the NASA Earth Science MEaSUREs Program and are available at www.remss.com. AIRS data were obtained through the Goddard Earth Sciences Data and Information Services Center (http://daac.gsfc.nasa.gov). The buoy data were obtained from National Data Buoy Center (http://www.ndbc.noaa.gov/). ARM data are made available through the US Department of Energy as part of the Atmospheric Radiation Measurement (ARM) Program. ARM Climate Research Facility TWP-C2 site data and MAGIC campaign data were used.
Edited by: M. Tesche

\section{References}

Ahlgrimm, M. and Randall, D. A.: Diagnosing monthly mean boundary layer properties from reanalysis data using a bulk boundary layer model, J. Atmos. Sci., 63, 998-1012, 2006.

Ao, C. O., Waliser D. E., Chan, S. K., Li, J.-L., Tian, B., Xie, F., and Mannucci, A. J.: Planetary boundary layer heights from GPS radio occultation refractivity and humidity profiles, J. Geophys. Res., 117, D16117, doi:10.1029/2012JD017598, 2012.

Albrecht, B. A., Jensen, M. P., and Syrett, W. J.: Marine boundary layer structure and fractional cloudiness, J. Geophys. Res., 100, 14209-14222, 1995.

Allen, G., Vaughan, G., Toniazzo, T., Coe, H., Connolly, P., Yuter, S. E., Burleyson, C. D., Minnis, P., and Ayers, J. K.: Gravitywave-induced perturbations in marine stratocumulus, Q. J. Roy. Meteor. Soc., 139, 32-45, 2013.

Bony, S. and Dufresne, J.-L.: Marine boundary layer clouds at the heart of tropical cloud feedback uncertainties in climate models, Geophys. Res. Lett., 32, L20806, doi:10.1029/2005GL023851, 2005.

Boers, R. and Eloranta, E. W.: Lidar measurements of the atmospheric entrainment zone and potential temperature jump across the top of the mixed layer, Bound.-Lay. Meteorol., 34, 357-375, 1986.

Boers, R., Eloranta, E. W., and Coulter, R. L.: Lidar observations of mixed layer dynamics: tests of parameterized entrainment models of mixed layer growth rate, J. Clim. Appl. Meteorol., 23, 247266, 1984.

Bretherton, C. S. and Wyant, M. C.: Moisture transport, lowertropospheric stability, and decoupling of cloud-topped boundary layers, J. Atmos. Sci., 54, 148-167, 1997.

Emeis, S., Schafer, K., and Munkel, C.: Surface-based Remote Sensing of the Mixing-layer Height - a Review, Meteorol. Z., 17, 621-630, 2008.

Guo, P., Kuo, Y.-H., Sokolovskiy, S. V., and Lenschow, D. H.: Estimating Atmospheric Boundary Layer Depth using COSMIC Radio Occultation Data, J. Atmos. Sci., 68, 1703-1713, 2011.

Hennemuth, B. and Lammert, A.: Determination of the Atmospheric Boundary Layer Height from Radiosonde and LidarBackscatter, Bound.-Lay. Meteorol., 120, 181-200, 2006.

Jason, L.: README document for AIRS Level-2 version 005 standard products. Goddard Earth Sciences Data And Information Services Center (Ed., National Aeronautics and Space Administration (NASA), 2008.

Jiang, Q. and Wang, S.: Impact of gravity waves on marine stratocumulus variability, J. Atmos. Sci., 69, 3633-3651, 2012.

Jones, C. R., Bretherton, C. S., and Leon, D.: Coupled vs. decoupled boundary layers in VOCALS-REx, Atmos. Chem. Phys., 11, 7143-7153, doi:10.5194/acp-11-7143-2011, 2011.

Jordan, N. S., Hoff, R. M., and Bacmeister, J. T.: Validation of Goddard Earth Observing System-version 5 MERRA planetary boundary layer heights using CALIPSO, J. Geophys. Res., 115, D24218, doi:10.1029/2009JD013777, 2010.

Karlsson, J., Svensson, G., Cardoso, S., Teixeira, J., and Paradise, S.: Subtropical Cloud-Regime Transitions: Boundary Layer 
Depth and Cloud-Top Height Evolution in Models and Observations, J. Appl. Meteorol. Clim., 49, 1845-1858, 2010.

Kawanishi, T., Sezai, T., Ito, Y., Imaoka, K., Takeshima, T., Ishido, Y., Shibata, A., Miura, M., Inahata, H., and Spencer, R. W.: The Advanced Microwave Scanning Radiometer for the Earth Observing System (AMSR-E), NASDA's contribution to the EOS for global energy and water cycle studies, IEEE T. Geosci. Remote Sens., 41, 184-194, 2003.

Klein, S. A. and Hartmann, D. L.: The seasonal cycle of low stratiform clouds, J. Climate, 6, 1587-1606, 1993

Kong, W. and Fan, Y.: Convective boundary layer evolution from lidar backscatter and its relationship with surface aerosol concentration at a location of a central China megacity, J. Geophys. Res.-Atmos., 120, 7928-7940, 2015.

Lambrigtsen, B. H. and Lee, S.-Y.: Coalignment and synchronization of the AIRS instrument suite, IEEE T. Geosci. Remote, 41, 343-351, 2003.

Leon, D. C., Wang, Z., and Liu, D.: Climatology of drizzle in marine boundary layer clouds based on 1 year of data from CloudSat and Cloud-Aerosol Lidar and Infrared Pathfinder Satellite Observations (CALIPSO), J. Geophys. Res., 113, D00A14, doi:10.1029/2008JD009835, 2008.

Leventidou, E., Zanis, P., Balis, D., Giannakaki, E., Pytharoulis, I., and Amiridis, V.: Factors affecting the comparisons of planetary boundary layer height retrievals from CALIPSO, ECMWF and radiosondes over Thessaloniki, Greece, Atmos. Environ., 74, 360-366, 2013.

Lewis, E. R., Wiscombe, W. J., Albrecht, B. A., Bland, G. L., Flagg, C. N., Klein, S. A., Kollias, P., Mace, G., Reynolds, R. M., Schwartz, S. E., Siebesma, A. P., Teixeira, J., Wood, R., and Zhang, M.: MAGIC: Marine ARM GPCI Investigation of Clouds. DOE/SC-ARM-12-020, US Department of Energy, 12 pp., 2012.

Luo, T., Yuan, R., and Wang, Z.: Lidar-based remote sensing of atmospheric boundary layer height over land and ocean, Atmos. Meas. Tech., 7, 173-182, doi:10.5194/amt-7-173-2014, 2014a.

Luo, T., Yuan, R. M., and Wang, Z.: On factors controlling marine boundary layer aerosol optical depth, J. Geophys. Res.-Atmos., 119, 3321-3334, 2014b.

Luo, T., Yuan, R. M., Wang, Z., and Zhang, Z.: Quantifying the Hygroscopic Growth of Marine Boundary Layer Aerosols by Satellite-Based and Buoy Observations, J. Atmos. Sci., 72, 1063-1074, 2015.

Mather, J. H. and Voyles, J. W.: The Arm Climate Research Facility: A Review of Structure and Capabilities, B. Am. Meteorol. Soc., 94, 377-392, 2013.

McGrath-Spangler, E. L. and Denning A. S.: Estimates of North American summertime planetary boundary layer depths derived from space-borne lidar, J. Geophys. Res., 117, D15101, doi:10.1029/2012JD017615, 2012.

McGrath-Spangler, E. L. and Denning A. S.: Global seasonal variations of midday planetary boundary layer depth from CALIPSO space-borne LIDAR, J. Geophys. Res.-Atmos., 118, 1226-1233, 2013.

Melfi, S. H., Sphinhirne, J. D., Chou, S. H., and Palm, S. P.: Lidar observations of the vertically organized convection in the planetary boundary layer over the ocean, J. Clim. Appl. Meteorol., 24, 806-821, 1985.
Minnis, P., Heck, P. W., Young, D. F., Fairall, C. W., and Snider, J. B.: Stratocumulus cloud properties derived from simultaneous satellite and island-based instrumentation during FIRE, J. Appl. Meteorol., 31, 317-339, 1992.

Norris, J. R.: Low cloud type over the ocean from surface observations. Part I: relationship to surface meteorology and the vertical distribution of temperature and moisture, J. Climate, 11, 369382, 1998.

Norris, J. R. and Leovy, C. B.: Interannual variability in stratiform cloudiness and sea surface temperature, J. Climate, 7, 19151925, 1994.

Overoye, K., Aumann, H. H., Weiler, M. H., Gigioli, G. W., Shaw, W., Frost, E., and McKay, T.: Test and calibration of the AIRS instrument, SPIE Proceedings, 3759, 254-265, 1999.

Pagano, T. S., Aumann, H. H., Hagan, D. E., and Overoye, K.: Prelaunch and in-flight radiometric calibration of the Atmospheric Infrared Sounder (AIRS), IEEE T. Geosci. Remote Sens., 41, 265-273, 2003.

Palm, S. P., Benedetti, A., and Spinhirne, J.: Validation of ECMWF global forecast model parameters using GLAS atmospheric channel measurements, Geophys. Res. Lett., 32, L22S09, doi:10.1029/2005GL023535, 2005.

Partain, P.: Cloudsat ECMWF-AUX auxiliary data process description and interface control document, available at: http://129.82. 109.192/ICD/ECMWF-AUX/ECMWF-AUX_PDICD_3.0.pdf (last access: 12 May 2016), 2004.

Piironen, P. and Eloranta, E. W.: Demonstration of a high spectral resolution lidar based on an iodine absorption filter, Opt. Lett., 19, 234-236, 1994.

Ratnam, M. V. and Basha, S. G.: A Robust Method to Determine Global Distribution of Atmospheric Boundary Layer Top from COSMIC GPS RO Measurements, Atmos. Sci. Lett., 11, 216222, 2010.

Randall, D. A., Abeles, J. A., and Corsetti, T. G.: Seasonal simulations of the planetary boundary layer and boundary-layer stratocumulus clouds with a general circulation model, J. Atmos. Sci., 42, 641-675, 1985.

Randall, D. A., Shao, Q., and Branson, M.: Representation of clear and cloudy boundary layers in climate models, in: Clear and Cloudy Boundary Layers, edited by: Holtslag, A. A. M. and Duynkerke, P. G., 305-322, Royal Netherlands Academy of Arts and Sciences, Amsterdam, 1998.

Randall, D. A., Wood, R. A., Bony, S., Colman, R., Fichefet, T., Fyfe, J., Kattsov, V., Pitman, A., Shukla, J., Srinivasan, J., Stouffer, R. J., Sumi, A., and Taylor, K. E.: Climate Models and Their Evaluation, in: Climate Change 2007: The Physical Science Basis. Contribution of Working Group I to the Fourth Assessment Report of the Intergovernmental Panel on Climate Change edited by: Solomon, S., Qin, D., Manning, M., Chen, Z., Marquis, M., Averyt, K. B., Tignor, M., and Miller, H. L., Cambridge University Press, Cambridge, United Kingdom and New York, NY, USA, 2007.

Sassen, K. and Wang, Z.: The Clouds of the Middle Troposphere: Composition, Radiative Impact, and Global Distribution, Surv. Geophys., 3, 677-691, 2012.

Seidel, D. J., Ao, C. O., and Li, K.: Estimating climatological planetary boundary layer heights from radiosonde observations: comparison of methods and uncertainty analysis, J. Geophys. Res., 115, D16113, doi:10.1029/2009JD013680, 2010. 
Sharon, T. M., Albrecht, B. A., Jonsson, H., Minnis, P., Khaiyer, M. M., VanReken, T. M., Seinfeld, J., and Flagan R.: Aerosol and cloud micro- physical characteristics of rifts and gradients in maritime stratocumulus clouds, J. Atmos. Sci., 63, 983-997, 2006

Shipley, S. T., Tracy D. H., Eloranta, E. W., Trauger, J. T., Sroga, J. T., Roesler, F. L., and Weinman, J. A.: A High Spectral Resolution Lidar to measure optical scattering properties of atmospheric aersols, Part I: Instrumentation and theory, Appl. Optics, 23, 3716-3724, 1983.

Stephens, G. L., Vane, D. G., Boain, R. J., Mace, G. G., Sassen, K., Wang, Z., Illingworth, A., J., O’Connor, E. J., Rossow, W. B., Durden, S. L., Miller, S. D., Austin, R. T., Benedetti, A., Mitrescu, C., and The CloudSat Science Team: THE CLOUDSAT MISSION AND THE A-TRAIN, B. Am. Meteorol. Soc., 83, 1771-1790, 2002.

Stull, R. B.: An Introduction to Boundary Layer Meteorology, Kluwer Academic Publishers, Norwell, MA, 1988.

Stull, R. B. and Eloranta, E. W.: Boundary Layer Experiment 1983, B. Am. Meteorol. Soc., 65, 450-456, 1984.

Susskind, J., Barnet, C., Blaisdell, J., Iredell, L., Keita, F., Kouvaris, L., Molnar, G., and Chahine, M.: Accuracy of geophysical parameters derived from Atmospheric Infrared Sounder/Advanced Microwave Sounding Unit as a function of fractional cloud cover, J. Geophys. Res., 111, D09S17, doi:10.1029/2005JD006272, 2006.

Tanelli, S., Durden, S. L., Im, E., Pak, K. S., Reinke, D. G., Partain, P., Haynes, J. M., and Marchand, R. T.: CloudSat's cloud profiling radar after two years in orbit: Performance, calibration, and processing, IEEE T. Geosci. Remote Sens., 46, 3560-3573, 2008.

Vanzanten, M. C., Duynkerke, P. G., and Cuijpers, J. W.: Entrainment parameterization in convective boundary layers, J. Atmos. Sci., 56, 813-828, 1999.

Vogelzang, D. and Holtslag, A.: Evaluation and model impacts of alternative boundary-layer height formulations, Bound.-Lay. Meteorol., 81, 245-269, 1996.

Wang, Z., Vane, D., Stephens, G., and Reinke, D.: Level 2 combined radar and lidar cloud scenario classification product process description and interface control document, JPL Rep., 22 pp., available at: http: //www.cloudsat.cira.colostate.edu/sites/default/files/products/ files/2B-CLDCLASS-LIDAR_PDICD.P_R04.20120522.pdf (last access: 25 February 2016), 2012.

Wentz, F. J., Gentemann, C., and Ashcroft, P.: On-orbit calibration of AMSR-E and the retrieval of ocean products, 83rd AMS Annual Meeting, American Meteorological Society, Long Beach, CA, 2003.

Wentz, F. J., Meissner, T., Gentemann, C., and Brewer, M.: Remote Sensing Systems AQUA AMSR-E Daily Environmental Suite on 0.25 deg grid, Version 7.0, Remote Sensing Systems, Santa Rosa, CA, available at: www.remss.com/missions/amsre (last access: 25 February 2016), 2014.
Winker, D. M., Hunt, W. H., and McGill M. J.: Initial performance assessment of CALIOP, Geophys. Res. Lett., 34, L19803, doi:10.1029/2007GL030135, 2007.

Winker, D. M., Vaughan, M. A., Omar, A., Hu, Y., Powell, K. A., Liu, Z., Hunt, W. H., and Young, S. A.: Overview of the CALIPSO mission and CALIOP data processing algorithms, J. Atmos. Ocean. Tech., 26, 2310-2323, 2009.

Wood, R. and Bretherton, C. S.: Boundary layer depth, entrainment, and decoupling in the cloud-capped subtropical and tropical marine boundary layer, J. Climate, 17, 3576-3588, 2004.

Wood, R. and Bretherton, C. S.: On the relationship between stratiform low cloud cover and lower-tropospheric stability, J. Climate, 19, 6425-6432, 2006.

Wyant, M. C., Wood, R., Bretherton, C. S., Mechoso, C. R., Bacmeister, J., Balmaseda, M. A., Barrett, B., Codron, F., Earnshaw, P., Fast, J., Hannay, C., Kaiser, J. W., Kitagawa, H., Klein, S. A., Köhler, M., Manganello, J., Pan, H.-L., Sun, F., Wang, S., and Wang, Y.: The PreVOCA experiment: modeling the lower troposphere in the Southeast Pacific, Atmos. Chem. Phys., 10, 4757-4774, doi:10.5194/acp-10-4757-2010, 2010.

Wyant, M. C., Bretherton, C. S., Wood, R., Carmichael, G. R., Clarke, A., Fast, J., George, R., Gustafson Jr., W. I., Hannay, C., Lauer, A., Lin, Y., Morcrette, J.-J., Mulcahy, J., Saide, P. E., Spak, S. N., and Yang, Q.: Global and regional modeling of clouds and aerosols in the marine boundary layer during VOCALS: the VOCA intercomparison, Atmos. Chem. Phys., 15, 153-172, doi:10.5194/acp-15-153-2015, 2015.

Xie, S., McCoy, R. B. , Klein, S. A., Cederwall, R. T. , Wiscombe, W. J., Jensen, M. P., Johnson, K. L., Clothiaux, E. E., Gaustad, K. L., Long, C. N., Mather, J. H. , McFarlane, S. A., Shi, Y., Golaz, J.-C., Lin, Y., Hall, S. D., McCord, R. A., Palanisamy, G., and Turner, D. D.: Clouds and More: ARM Climate Modeling Best Estimate Data, B. Am. Meteorol. Soc., 91, 13-20, 2010.

Xie, F., Wu, D. L., Ao, C. O., Mannucci, A. J., and Kursinski, E. R.: Advances and Limitations of Atmospheric Boundary Layer Observations with GPS Occultation over Southeast Pacific Ocean, Atmos. Chem. Phys., 12, 903-918, 2012.

Yue, Q., Kahn, B. H., Fetzer, E. J., and Teixeira, J.: Relationship between marine boundary layer clouds and lower tropospheric stability observed by AIRS, CloudSat, and CALIOP, J. Geophys. Res., 116, D18212, doi:10.1029/2011JD016136, 2011.

Zhang, C., Wang, Y., and Hamilton, K.: Improved representation of boundary layer clouds over the southeast Pacific in ARW-WRF using a modified tiedtke cumulus parameterization scheme, Mon. Weather Rev., 139, 3489-3513, 2011.

Zhou, X., Kollias, P., and Lewis, E. R.: Clouds, precipitation, and marine boundary layer structure during the magic field campaign, J. Climate, 28, 2420-2442, 2015.

Zuidema, P., Painemal, D., Szoeke, S. de, and Fairall, C.: Stratocumulus cloud-top height estimates and their climatic implications, J. Climate, 22, 4652-4666, 2009. 